\title{
STUDI BIOLOGI IKAN BELIDA (Notopterus chitala) DI DAERAH ALIRAN SUNGAI BATANGHARI, PROPINSI JAMBI
}

\author{
Susilo Adjie"), Husnah") dan Abdul Karim Gaffar")
}

\begin{abstract}
ABSTRAK
Penelitian biologi ikan belida di daerah aliran Sungai Batanghari, Propinsi Jambi telah dilakukan pada bulan Mei sampai dengan bulan November 1996 bertujuan untuk mendapatkan informasi tentang sifat pertumbuhan, reproduksi, habitat dan kebiasaan makan. Sampel ikan sebanyak 84 ekor hasil tangkapan nelayan diukur panjang dan bobotnya di lapangan dan pengamatan isi usus dan gonad dilakukan di laboratorium Hidrobiologi Loka Penelitian Perikanan Air Tawar Palembang.

Hasil penelitian menunjukkan bahwa ikan belida yang tertangkap di daerah aliran Sungai Batanghari pada ikan betina pola pertumbuhannya isometrik dengan persamaan hubungan panjang bobot $\mathrm{W}=0.000085 \mathrm{~L}^{26+}$ sedangkan pada ikan jantan pertumbuhannya bersifat allometrik dengan persamaan hubungan panjang-bobot $\mathrm{W}=0.000001 \mathrm{~L}^{330}$. Ikan betina lebih gemuk daripada ikan jantan. Ikan belida bersifat carnivorous dengan pakan utamanya adalah ikan. Fekunditas berkisar antara 260-6080 butir, diameter telur $=0,15-3,76 \mathrm{~mm}$ dan indek gonado-somatis $=0,26-1,85 \%$. Ikan belida hidup di perairan sungai terutama di aliran yang banyak terdapat kayu mati dan pada musim hujan ikan-ikan tersebut menyebar ke kawasan rawa banjiran.
\end{abstract}

\section{ABSTRACT: Biological study on belida, Notopterus chitalu in Batanghari River Basin, Jambi Province. By: Susilo Adjie, Husnah and Abdul Karim Gaffar.}

A study on some biological aspects of "belida", Notopterus chitala was carried out in Batanghari River from May to November 1996 in order to find out the information on its growth pattern, condition factor, reproduction, habitat and feeding habit. Samples from fishermen were analyzed in the laboratory for gut content and fecundity.

The results showed that belida is a carnivorous fish. Growth pattern of male fish was allometric while that of female fish was isometric. Females are more plump than males. Fecundity was 260 . 6080 egg's, with egg diameter varied from 0.15 to $3.76 \mathrm{~mm}$ and gonado somatic index was 0.26 . $1.85 \%$. The fish are found mainly in the stream which is rich of dead trees and some of them reach the swampy forest cluring the rainy season.

\section{KEYWORDS: biology, Notopterus chitala, Batanghari River Basin}

\section{PENDAHULUAN}

Perairan umum sungai dan lebak di Indonesia bagian barat yakni.Jawa, Sumatera dan Kalimantan dihuni oleh tiga jenis anggota marga Notopterus yaitu Notopterus notopterus, Notopterus chitala dan Notopterus borneensis. Kedudukan ikan belida dalam taksonomi, menurut Smith (1945) adalah sebagai herikut; phylum: Chordata, kelas: Pisces, subkelas: Teleostomi, ordo: Isospondyli, famili: Notopteridae, genus: Notopterus, spesies: Notopterus chitala. Dari tiga jenis yang ada di perairan Indonesia, hanya belida (Notopterus chitala) yang bernilai ekonomis penting khususnya bagi masyarakat Sumatera Selatan terutama sebagai bahan baku untuk pembuatan empekempek, kerupuk, kemplang dan sebagainya. Di India ikan ini mencapai panjang lebih dari satu meter sedang di Thailand umumnya hanya mencapai 70 $75 \mathrm{~cm}$ (Smith, 1945) dan di Indonesia dilaporkan dapat mencapai $87,5 \mathrm{~cm}$ (Weber \& De Beaufort, 1913). Menurut penelitian terdahulu (Adjie \& Utomo, 1994) ikan belida di perairan Lubuk Lampam Sumatera Selatan dapat mencapai panjang $83 \mathrm{~cm}$. Ikan ini dikenal oleh masyarakat Sumatera Selatan dengan sebutan belido, di Kalimantan Barat belida sedang di Kalimantan Selatan dan Kalimantan Tengah disebut ikan pipih.

Menurut Smith (1945) perkembangbiakan belida telah diteliti di Thailand dan terbukti bahwa pada tiap kali memijah hanya satu kandung telur (ovarium) yang berkembang. Tetapi belum diketahui apakah kandung telur tersebut bergilir di antara yang kanan dengan yang kiri atau memang selamanya hanya satu kandung telur yang berkembang. Pada waktu pemijahan induk belida menempelkan telur-telurnya pada benda-benda yang berada 1,5-2 m di bawah permukaan air. Telur ikan yang telah dibuahi dijaga oleh induk jantan

Peneliti pada Loka Penelitian Perikanan Air Tawar Palembang 
dari gangguan makhluk lain. Untuk menghindari pencemaran telur dari lumpur dan sisa tumbuhan, induk jantan mengibas-ngibaskan sirip dubur dan ekornya. Jumlah yang dikeluarkan dalam satu kali pemijahan berkisar antara 5.000-10.000 butir. Masa pengeraman sebelum menetas adalah 5-6 hari pada suhu $33^{\circ} \mathrm{C}$.

Menurut penelitian terdahulu (Adjie \& Utomo, 1994) di perairan Lubuk Lampam, Sumatera Selatan ikan belida termasuk pemangsa (carnivora) dan makanan utamanya adalah ikan-ikan kecil dan udang. Ikan belida berukuran 81 dan $83 \mathrm{~cm}$ dengan bobot 4 dan $6 \mathrm{~kg}$ mempunyai fekunditas telur 1.194 dan 8.320 butir. Tempat pemijahan berada di perairan sungai yang banyak terdapat tempat berlindung seperti ranting-ranting kayu. Musim pemijahannya pada saat air besar yaitu pada bulan November-Januari. Ikan ini sering tertangkap di perairan sungai dan rawang di mana ikan-ikan kecil banyak yang berlindung di situ sebagai makanan utama ikan belida tersebut (Adjie \& Utomo, 1994).

Ikan tersebut oleh pemerintah daerah setempat telah ditetapkan sebagai maskot Dati I Sumatera Selatan. Menurut Suwelo et al. (1986) ikan belida termasuk ikan air tawar yang telah dilindungi. Di Propinsi Jambi ikan ini sebagai ikan unggulan daerah yang habitatnya tersebar di daerah aliran sungai (DAS) Batanghari beserta anak-anak sungainya yakni Sungai Batang Tebo, Sungai Batang Tabir dan Sungai Batang Tembesi. Walaupun masih sering tertangkap di DAS Batanghari, populasi ikan tersebut dikhawatirkan terancam kelestariannya (Anonim, 1993).

Penangkapan ikan belida memuncak pada musim kemarau. Alat tangkap yang digunakan adalah pancing, empang arat dan jaring insang. Di sebagian tempat dipergunakan jaring khusus untuk belida, yakni jaring insang yang dipasang mendatar di permukaan air untuk menangkap belida yang biasa muncul ke permukaan air (Ondara \& Dharyati, 1993).

Pengetahuan tentang biologi ikan belida meliputi antara lain sifat pertumbuhan, faktor kondisi, aspek reproduksi dan pola kebiasaan makan diperlukan baik dalam upaya perlindungannya di habitat alami maupun usaha ke arah domestikasi.

Penelitian ini bertujuan untuk mendapatkan informasi tentang sifat biologi dan lingkungan hidup ikan belida sebagai bahan pertimbangan dalam menentukan pola pelestarian ikan langka.

\section{BAHAN DAN METODE}

Penelitian dengan metode survai dilakukan di DAS Batanghari, Propinsi Jambi pada bulan Mei,
Juli, September dan November 1996. Sampel ikan belida sebanyak 84 ekor didapatkan dari hasil tangkapan nelayan pada beberapa tempat di Kabupaten Bungo Tebo dan Kabupaten Batanghari yang menggunakan alat tangkap pancing. rawai, jaring dan bubu.

Parameter yang diukur dan diamati aclalah panjang total, bobot, tingkat kematangan gonad, diameter telur dan fekunditas, serta karakteristik habitat.

Tingkat kematangan gonad diklasifikasikan menurut Nikolsky (1963), indek gonado-somatis dihitung menurut Effendie (1992).

$$
\text { I GS }=\frac{\text { bobot } \text { gonad }}{\text { bobot ikan }} \times 100 \%
$$

Fekunditas dihitung mengikuti cara Bagenal (1968).

$$
\mathrm{X}: \mathrm{x}=\mathrm{V}: \mathrm{v}
$$

di mana:

$\mathrm{X}=$ Jumlah telur di dalam gonad yang akan dicari (fekunditas).

$\mathrm{x}=$ Jumlah telur dari sebagian kecil gonad.

$\mathrm{V}=$ Isi (volume) seluruh gonad.

$\mathrm{v}=$ Isi (volume) sebagian gonad.

Faktor kondisi (KTL) mengikuti metode Tesch (1968).

$$
\mathrm{K} T L=\frac{\mathrm{W} 10^{5}}{\mathrm{~L}^{3}}
$$

di mana:

$\mathrm{W}=$ Bobot ikan (gram).

$\mathrm{L}=$ Panjang total $(\mathrm{mm})$.

Hubungan panjang-bobot dihitung mengikuti metode Tesch (1968).

di mana:

$$
\mathrm{W}=\mathrm{a} \mathrm{L}^{\mathrm{b}}
$$

W = Bobot ikan (gram).

$\mathrm{L} \quad \quad=$ Panjang total $(\mathrm{mm})$.

$\mathrm{a} \& \mathrm{~b} \quad=$ Parameter yang dicari.

Kebiasaan makan dinyatakan dengan indek bagian terbesar (Natarajan \& Jhingran, 1961).

$$
I_{i}=\frac{V_{i} \times O_{i}}{\sum\left(V_{i} \times O_{i}\right)} \times 100
$$

di mana:

$I_{1}=$ Indeks bagian terbesar (Index of preponderance).

$\mathrm{V}_{\mathrm{i}} \quad=$ Persentase volume satu macam makanan.

$\mathrm{O}_{1}=$ Persentase frekuensi satu macam makanan. 
Identifikasi makanan ikan belida mengacu pada Needham \& Needham (1962), Pennack (1978), Whitford \& Schumacher (1973).

Pemeriksaan mutu air pada setiap stasiun pengamatan (Lampiran 1) meliputi parameter fisika dan kimia yaitu suhu, kecerahan, konduktivitas, $\mathrm{pH}$, alkalinitas, oksigen, kesadahan, fosfat, nitrat, sulfat dan TDS, mengacu pada metode baku APHA et al. (1980).

\section{HASIL DAN BAHASAN}

\section{Pertumbuhan}

Hasil analisis hubungan panjang-bobot dan faktor kondisi ikan belida menunjukkan bahwa:

Hubungan panjang-bobot ikan belida jantan mengikuti persamaan $\mathrm{W}=0.000001 \mathrm{~L}^{3.30}$ dan ikan belida betina mengikuti persamaan $\mathrm{W}=0.000085$ $\mathrm{L}^{2.64}$. Menurut Tesch (1968) bila pada persamaan $\mathrm{W}=\mathrm{a} \mathrm{L}^{\mathrm{b}}$ mempunyai nilai $\mathrm{b}=3$ maka pertumbuhan ikan tersebut bersifat isometrik dan jika $b>3$ atau $\mathrm{b}<3$ pertumbuhannya bersifat allometrik. Untuk jelasnya lihat Tabel 1.

Nilai faktor kondisi untuk ikan belida jantan adalah 0,84 sedangkan untuk ikan betina $=1,096$. Hal ini berarti bahwa rata-rata ikan belida betina lebih gemuk dibandingkan dengan ikan belida jantan.

\section{Biologi reproduksi}

Perkembangan tingkat kematangan gonad ikan belida betina selama penelitian memperlihatkan bahwa ikan betina dengan tingkat kematangan gonad IV atau ikan yang siap untuk memijah ditemukan pada tiap bulan survai dan pada waktu yang bersamaan juga ditemukan ikan betina dengan tinglkat kematangan yang berbeda. Data tersebut memberikan indikasi bahwa ikan belida dapat matang gonad sepanjang tahun. Untuk jelasnya lihat Tabel 2 .

Indeks gonado-somatis, fekunditas dan sebaran diameter telur pada berbagai ukuran induk ikan belida dapat dilihat pada Tabel 3. Banyaknya telur dalam gonad memperlihatkan variasi yang sangat besar yang mengakibatkan nilai indek gonadosomatis bervariasi dari $0,261 \%$ sampai $1,855 \%$, dengan fekunditas berkisar antara 260-6.080 butir. Jumlah telur ikan belida yang tertangkap pada waktu yang sama tidak menunjukkan hubungan dengan ukuran ikan. Diduga induk ikan belida melepaskan telurnya pada waktu yang tidak bersamaan, sehingga ikan dengan fekunditas kecil diduga ikan yang baru selesai memijah, sedangkan ikan yang fekunditasnya besar dengan diameter telur lebih dari $3 \mathrm{~mm}$ adalah induk yang akan segera memijah. Data tersebut juga memberikan indikasi bahwa ikan belida memijah beberapa kali dalam setahun. Hal ini didukung oleh penelitian Utomo et al. (1990) yang meneliti tentang aspek biologi ikan lais dan penelitian oleh Gaffar et al. (1991) tentang pola pertumbuhan, makanan dan fekunditas ikan semah. Kedua penelitian tersebut menyimpulkan bahwa indikasi ikan yang tidak mengenal musim pemijahan bila berdasarkan hasil pengamatan terhadap tingkat kematangan gonad (TKG) pada tiap bulan ditemukan sampel yang matang telur.

Dibandingkan dengan jenis ikan lain, semah misalnya dengan panjang $46-83,5 \mathrm{~cm}$ mempunyai fekunditas 9.180-63.360 butir, maka ikan belida mempunyai fekunditas rendah. Hal ini dapat menyebabkan peremajaan populasi ikan belida lambat dan bila penangkapan tidak terkendali dapat mengakibatkan cepat langkanya ikan tersebut.

Tabel 1. Hubungan panjang-bobot dan faktor kondisi ikan belida (Notopterus chitala) yang tertangkap di Sungai Batanghari tahun 1996.

Table 1. Length-weight relationship and condition factor of "belida" (Notopterus chilata) caught in Batanghari River, 1996.

\begin{tabular}{|c|c|c|c|c|c|}
\hline \multirow[b]{2}{*}{$\begin{array}{l}\text { Jenis kelamin } \\
\text { Sex }\end{array}$} & \multirow[b]{2}{*}{$\mathrm{N}$} & \multicolumn{2}{|c|}{ Kisaran (Range) } & \multirow{2}{*}{$\begin{array}{c}\text { Regresi } \\
\text { Regression } \\
\mathrm{W}=\mathrm{aL}^{\mathrm{b}}\end{array}$} & \multirow[b]{2}{*}{$\begin{array}{l}\text { Faktor kondisi } \\
\text { Condition factor }\end{array}$} \\
\hline & & $\begin{array}{c}\text { Panjang } \\
\text { Length } \\
(\mathrm{mm})\end{array}$ & $\begin{array}{l}\text { Bobot } \\
\text { Weight } \\
\text { (g) }\end{array}$ & & \\
\hline Jantan (Male) & 38 & $420-880$ & $450-5,700$ & $\mathrm{~W}=0.000001 \mathrm{~L}^{3.30}$ & 0.840 \\
\hline Betina (Female) & 46 & $350-970$ & $800-7000$ & $W=0.000085 \mathrm{~L}^{2.64}$ & 1.096 \\
\hline
\end{tabular}


Tabel 2. Perkembangan tingkat kematangan gonad ikan belida (Notopterus chitala) yang tertangkap di Sungai Batanghari pada tahun 1996.

Table 2. Gonadal maturity of belida (Notopterus chitala) caught in Batanghari river, in 1996 .

\begin{tabular}{|c|c|c|c|c|c|c|}
\hline \multirow{2}{*}{\multicolumn{2}{|c|}{$\begin{array}{l}\text { Bulan pengamatan } \\
\text { Month of observation }\end{array}$}} & \multicolumn{5}{|c|}{$\begin{array}{l}\text { Tahap kematangan gonad } \\
\text { Stage of gonadal maturity }\end{array}$} \\
\hline & & \multirow{2}{*}{ I } & \multirow{2}{*}{ II } & \multirow{2}{*}{$\frac{\text { III }}{60}$} & \multirow{2}{*}{$\frac{\text { IV }}{40}$} & \multirow{2}{*}{ V } \\
\hline Mei (May) & $(\%)$ & & & & & \\
\hline Juli (July) & $(\%)$ & - & - & 16.4 & 66.4 & 16.6 \\
\hline September & $(\%)$ & - & 60 & - & 40 & - \\
\hline November & $(\%)$ & 25 & 25 & . & 50 & - \\
\hline
\end{tabular}

Tabel 3. Indeks gonado somatis, fekunditas dan diameter telur ikan belida betina yang tertangkap di Sungai Batanghari tahun 1996.

Table 3. Gonado-somatic index, fecundity and egg diameter of female belida caught in Batanghari river in 1996.

\begin{tabular}{|c|c|c|c|c|c|c|}
\hline $\begin{array}{l}\text { Bulan } \\
\text { Month }\end{array}$ & $\begin{array}{l}\text { Bobot total } \\
\text { Total weight } \\
\text { (g) }\end{array}$ & $\begin{array}{c}\text { Panjang total } \\
\text { Total length } \\
(\mathrm{mm})\end{array}$ & $\begin{array}{l}\text { Bobot gonad } \\
\text { Weight of } \\
\text { gonad } \\
\text { (g) }\end{array}$ & $\begin{array}{l}\text { GSI } \\
(\%)\end{array}$ & $\begin{array}{l}\text { Fekunditas } \\
\text { (telur) } \\
\text { Fecundity } \\
\text { (egg) }\end{array}$ & $\begin{array}{c}\text { Diameter } \\
\text { telur } \\
\text { Egg diameter } \\
(\mathrm{mm})\end{array}$ \\
\hline \multirow[t]{2}{*}{ Mei $\left(M a y^{\prime}\right)$} & 4,400 & 7,900 & 14.2 & 0.375 & 1,085 & $0.87-3.10$ \\
\hline & 6,600 & 9,200 & 42.2 & 0.639 & 6,080 & $0.21-3.31$ \\
\hline \multirow[t]{4}{*}{ Juli (July) } & 3.650 & 7,900 & 14.0 & 0.383 & 816 & $0.90-2.50$ \\
\hline & 4,750 & 8,000 & 12.4 & 0.261 & 260 & $0.25-2.50$ \\
\hline & 4,000 & 7,000 & 12.9 & 0.322 & 774 & $0.15-2.50$ \\
\hline & 2.900 & 7,100 & 53.8 & 1.855 & 4,950 & $0.90-3.50$ \\
\hline \multirow[t]{2}{*}{ September } & 3,100 & 7,200 & 15.3 & 0.493 & 3.673 & $0.15-2.62$ \\
\hline & 1,900 & 6,300 & 24.2 & 1.273 & 3,105 & $0.25-2.62$ \\
\hline \multirow[t]{2}{*}{ November } & 7,000 & 9,700 & 87.0 & 1.243 & 3,888 & $0.25-3.76$ \\
\hline & 6,700 & 9,300 & 42.5 & 0.634 & 3,255 & $0.15-3.55$ \\
\hline
\end{tabular}

\section{Pakan Alami}

Dari hasil analisis isi usus ikan belida terlihat bahwa berdasarkan urutan indeks bagian terbesar terlihat bahwa pakan utama ikan belida adalah ikan dengan pakan pelengkap yaitu udang dan serangga air.

Sisa tumbuhan yang terdapat di dalam usus ikan belida berdasarkan struktur alat pencernaannya dianggap bukan bagian dari pakannya tapi diduga substrat serangga yang ikut tertelan waktu ikan menangkap serangga atau udang. Untuk jelasnya lihat Tabel 4 .

\section{Habitat}

Ikan belida menyenangi perairan sungai yang banyak terdapat pohon kayu yang tumbang dan di rawa banjiran yang berhutan, karena diduga batang kayu baik yang masih hidup maupun yang telah mati merupakan rumpon bagi ikan kecil dan berfungsi sebagai media bagi udang dan serangga air, selain merupakan sumber makanan bagi ikan belida juga sebagai substrat tempat menempelkan telurnya yang sudah dibuahi.

Pada saat debit air kecil di musim kemarau ikan belida cenderung tinggal di perairan sungai. sedang- 
Tabel 4. Komposisi dan indeks bagian terbesar makanan ikan belida (Notopterus chitala) yang tertangkap di Sungai Batanghari tahun 1996.

Table 4. Composition and indexs of preponderance of gut content of belida (Notopterus chitala) caught in Batanghari river, 1996.

\begin{tabular}{lc}
\hline \multicolumn{1}{c}{$\begin{array}{c}\text { Jenis pakan } \\
\text { Food items }\end{array}$} & $\begin{array}{c}\text { Indeks bagian terbesar (\%) } \\
\text { Index of prepoderance (\%) }\end{array}$ \\
\hline Ikan (Fish) & 78.94 \\
Udang (Shrimp) & 3.61 \\
Serangga (Insect) & 0.09 \\
Cacing (Planarian) & 0.01 \\
Gastropoda & 0.01 \\
Bahan tumbuhan (Plant materials) & 6.99 \\
Bahan tak teridentifikasi (Unidentified & \\
materials) & 10.36 \\
\hline
\end{tabular}

kan pada saat air melimpah di musim hujan mereka menyebar ke rawa banjiran dan persawahan baik untuk memijah maupun untuk mencari makanan.

Keadaan kondisi perairan dapat dilihat dari nilai parameter fisika, kimia air yang menunjukkan sifat reaksi sekitar netral, bersifat lunak dengan alkalinitas relatif rendah dan kandungan hara fosfor dan nitrat rendah (Tabel 5). Kondisi perairan demikian tergolong kurang subur namun tidak berbahaya bagi kehidupan ikan dan organisme air lainnya.

Tabel 5. Keadaan kondisi fisika-kimia perairan di Sungai Batanghari pada bulan Mei-November 1996.

Table 5. Physico-chemical characters of Batanghari River on May-November 1996.

\begin{tabular}{|c|c|c|c|c|c|c|c|c|c|}
\hline \multirow{2}{*}{$\begin{array}{c}\text { Peubah } \\
\text { Parameter }\end{array}$} & \multicolumn{9}{|c|}{ Titik pengamatan (Fixed observation point) } \\
\hline & PPJ & PMS & MJ & SNM & MP & SBK & AT & KPS & SB \\
\hline Suhu (Temperature) $\left(0^{\circ} \mathrm{C}\right)$ & 28 & 28 & 28.5 & 28.5 & 28 & 28 & 28 & 28 & 28 \\
\hline Kecerahan (Transparency) $(\mathrm{cm})$ & - & 42 & 42 & - & - & 40 & 30 & 20 & 20 \\
\hline Konduktivitas (Conductivity) ( $\mu \mathrm{mhos}$ ) & 28.9 & 60.5 & - & 26 & 28.9 & $\cdot$ & 25.3 & - & 33.5 \\
\hline $\mathrm{pH}$ & 7.5 & 7.5 & 7 & 6.5 & 7 & 7 & 6.5 & 6.5 & 7 \\
\hline Alkalinitas (Alkalinity) ( $\left.\mathrm{mg} / \mathrm{L} \mathrm{CaCO}_{3}\right)$ & 43 & 31.8 & 24.2 & 14.2 & 18.2 & 19 & 17.4 & 16.8 & 9.4 \\
\hline $\mathrm{O}_{2}(\mathrm{mg} / \mathrm{L})$ & 7.5 & 6.7 & 6.6 & 6.8 & - & 7 & 6 & 6.7 & 9.4 \\
\hline Kesadahan (Hardness) (mg/L $\left.\mathrm{CaCO}_{3}\right)$ & 156 & 110 & 74 & 45 & 65 & 58 & 56 & 55 & 66 \\
\hline $\mathrm{PO}_{2}(\mathrm{mg} / \mathrm{L})$ & - & 0.08 & 0.07 & & - & 0.09 & - & - & \\
\hline $\mathrm{NO}_{3}(\mathrm{mg} / \mathrm{L})$ & - & 0.08 & 0.07 & - & - & 0.07 & - & - & - \\
\hline $\mathrm{SO}_{4}(\mathrm{mg} / \mathrm{L})$ & - & 5.8 & 6.56 & - & - & 5.4 & . & - & - \\
\hline TDS (g) & 0.01 & 0.02 & $\cdot$ & 0.02 & 0.01 & $\cdot$ & 0.01 & $\cdot$ & 0.01 \\
\hline
\end{tabular}

Catatan (Remark):

$\begin{array}{lllll}\text { PPJ : } & \text { Pulau Punjung } & \text { SNM : } & \text { Senamat } \\ \text { AT : } & \text { Ampelu Tuo } & \text { PMS : } & \text { Pulau Musang (Musang lsland) } \\ \text { MP : } & \text { Mampun } & \text { KPS : } & \text { Kembang Paseban } \\ \text { MJ : } & \text { Mangun Jaya } & \text { SBK : } & \text { Sungai Bengkal (Bengliver) } \\ \text { SB : } & \text { Sungai Baung (Baung river) } & \\ \text { - : } & \text { Tidak diukur (not measured) } & \end{array}$

Lihat gambar Lampiran 1 (See figure at Annex 1) 


\section{KESIMPULAN DAN SARAN}

1. Ikan belida bersifat carnivorous dengan makanan utamanya adalah ikan. Pertumbuhan ikan jantan bersifat allometrik dan ikan betina bersifat isometrik. Ikan belida betina lebih gemuk daripada ikan belida jantan.

2. Fekunditas berkisar antara 260-6.080 butir dengan diameter telurnya $0,15-3,76 \mathrm{~mm}$ dan indeks kematangan gonad 0,26-1,85\%. Musim pemijahan diduga terjadi beberapa kali sepanjang tahun. Tempat pemijahan di perairan sungai yang banyak terdapat tempat berlindung. seperti ranting-ranting kayu, di hutan rawang dan di persawahan.

3. Habitat ikan belida adalah perairan sungai yang banyak terdapat ranting-ranting atau batang. batang kayu baik yang masih hidup maupun mati dan di lebak-lebak. Pada saat air besar ikan belida beruaya menuju ke hutan rawang dan persawahan untuk memijah dan mencari makanan.

4. Disarankan perlu adanya pembatasan penangkapan ikan belida matang telur dan ikan yang masih berukuran kecil sebagai upaya melestarikan ikan tersebut. Selain itu perlu adanya penelitian lanjutan mengenai domestikasi ikan belida yang mengarah ke budi dayanya sehingga dapat mengurangi tekanan penangkapannya di alam.

\section{DAFTAR PUSTAKA}

Adjie. S. dan Utomo. A.D. 1994. Aspek biologi ikan belida di perairan sekitar Lubuk Lampam Sumatera Selatan. Kumpulan makalah seminar penyusunan, pengolahan dan evaluasi hasil penelitian perikanan perairan umum. Palembang. 174-176.

Anonim. 1993. Laporan Akhir Studi Identifikasil inventarisasi Plasma Nutfah Perikanan Perairan Umum. Dinas Perikanan Daerah Tingkat I Jambi. 119 hal.

APHA. AWWA. WPCF. 1980. Standard Methods for the Examination Water and Wastewater. 15 Edition. American Public Health Association. Washington. $1135 \mathrm{pp}$
Bagenal, 'TB. 1968. Fekundity. In Ricker. W.E (ed) Methods for Assesements of Fish Productions. IBP Handbook No.3. Black well Scientific publications 159-181

Effendie. M.I. 1992. Metode Biologi Perikanan. Yayasan Agromedia. Bogor. 112 hal.

Gaffar, A.K.. Utomo, A.D. dan Adjie. S. 1991. Pola pertumbuhan, makanan dan fekunditas ikan semah (Labeobarbus douronensis) di Sungai Komering Bagian Hulu Sumatera Selatan. Bull. Penel. Perik. Darat. 10(1): 17-22.

Natarajan, A.V. and Jhingran. A.G. 1961. Index of Preponderance a method of grading the food elements in the stomach of fishes. Indian J. Fish. 8 (1): 54-59.

Needham. J.G. and Needham, D.R. 1962. Freshwate. Biology'. Holden Day Inc. Sanfrancisco. 108 pp.

Nikolsky, G.V. 1963. The Ecology of Fishes. Academic Press. London and New York. 352 pp.

Ondara dan Dharyati, E. 1993. Kerabat ikan belida (Suku: Notopteridae) di Indonesia, terutama kasus di Sumatera Selatan. Prosiding Simposium Perikancen Indonesia I. Jakarta.344-358.

Pennack, R.W. 1978. Freshwater Invertebrates of the United States. Jhon Wiley and Sons. New York. 803 pp.

Smith, H.N. 1945. The fresh-water fishes of Siam. o1 Thailand Smithsonian Institution United States National Museum. Bulletin 188. Washington. 57 . 59.

Suwelo, I.S., Supangkat, S. dan Yunita, C. 1986. Limnologi dan konservasi lingkungan hidup pelestarian rawa. danau dan sungai habitat biota langka. Prosiding Elspose Limnologi dan Pembangunan. Bogor: 87-95.

Tesch. F.W'. 1968. Age and Groeth. In Ricker. W. E. (ed) Methods for Assesementh of Fish Productions. IBP Handbook No.3. Blackwell Scientific Publlications. 93-123.

Utomo, A.D, Adjie, S. dan Asyari. 1990. Aspek biolog ikan lais di Perairan Lubuk Lampam. Sumatera Selatan. Bull. Penel. Perik. Darat. 9(2): 105-111.

Weber and De Beauford. 1913. The Fishess of the Indo. Australian Archipelago. Leiden. 10-11.

Whitford. J.A. and Scumacher. 1973. A Manual of Fresh water Algae. Universitets Bokhandelen. Sparks Press Faleigh. N.C. 324 pp. 


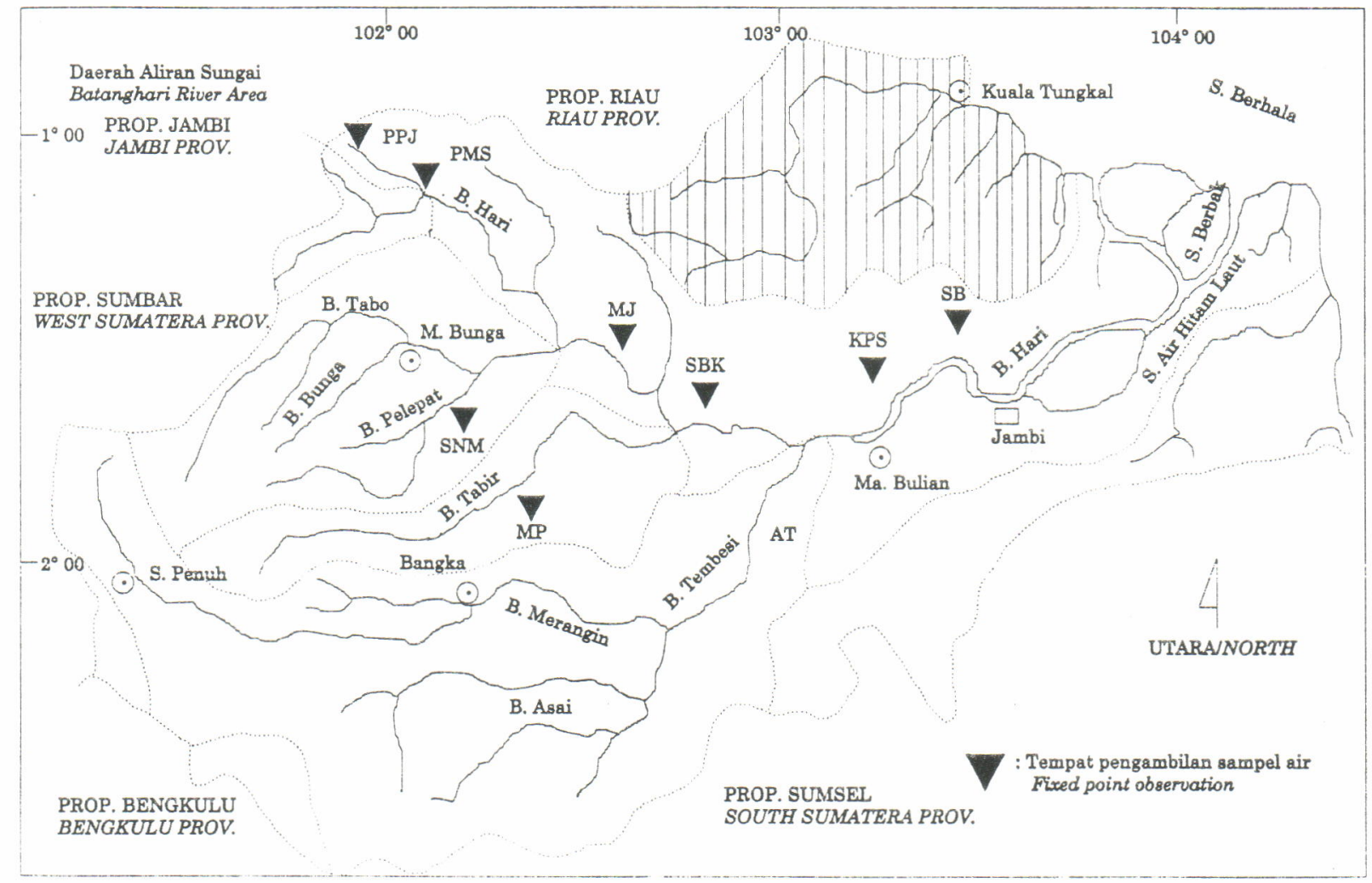

Gambar 1. Peta lokasi pengambilan sampel air dari DAS Sungai Batanghari.

Figure. 1. Fixed points observation at Batanghari River area. 